\title{
EVALUACIÓN DE LA RESISTENCIA A LA SARNA POLVOSA EN GENOTIPOS DE Solanum phureja BAJO CONDICIONES CONTROLADAS A PARTIR DE TUBÉRCULOS SEMILLA
}

Fecha de recepción: 23 de septiembre de 2014 • Fecha de aceptación: 27 de octubre de 2014

\begin{abstract}
EVALUATION OF RESISTANCE TO POWDERY SCAB IN Solanum phureja GENOTYPES UNDER CONTROLLED CONDITIONS USING SEED-TUBERS
\end{abstract}

Liliana Andrea Ramírez Franco ${ }^{1}$ Catalina María Zuluaga Amaya $\bullet$ José Miguel Cotes Torres ${ }^{3}$

\section{RESUMEN}

Se realizó un bioensayo con 88 genotipos de Solanum phureja para evaluar la respuesta a la sarna polvosa de la papa. Para la obtención del material vegetal, se sembraron tubérculos en bolsas plásticas de 3 kg de capacidad. Cada planta fue inoculada a los 25 días después de siembra, con una aplicación directa a la raíz de $10 \mathrm{~g}$ de suelo infectado a una concentración de 7 × $10^{6}$ quistosoros. Después de los 50 días de la inoculación, en estado de floración, se observó la presencia de agallas en raíces. Las plantas asintomáticas, aquellas donde no se observaron estructuras o síntomas del patógeno, fueron evaluadas mediante la técnica de PCR con primer específicos para la detección de Spongospora subterranea f. sp. subterranea. Los resultados mostraron que 57 genotipos, presentaron el 100\% de incidencia; 21 genotipos no presentaron la enfermedad; y los 10 restantes presentaron valores intermedios de incidencia. La variedad testigo Criolla Colombia presentó un 90,87\% de incidencia. La severidad media estimada de todos los genotipos osciló entre 0 y 4,68\%, para los genotipos resistentes y susceptibles, respectivamente.

Palabras clave: Quistosoros, bioensayos, incidencia, severidad.

1 Ing. Agr. Estudiante de Maestría en Ciencias Agrarias. liaramirezfr@unal.edu.co Institución: Universidad Nacional Colombia - Sede Medellín - Facultad de Ciencias Agrarias - Departamento de Ciencias Agronómicas - Cll. 59A No. 63-20 - Núcleo El Volador, Medellín - Colombia.

2 Ing. Agr. MSc. Profesor Asistente. catazuluaga81@gmail.com. Politécnico Colombiano Jaime Isaza Cadavid. Facultad de Ciencias Agrarias. Cr 48 No. 7-151 Medellín - Colombia

3 Ing. Agr. MSc. DSc. Profesor Asociado. jmcotes@unal.edu.co Institución: Universidad Nacional Colombia - Sede Medellín - Facultad de Ciencias Agrarias - Departamento de Ciencias Agronómicas - Cll. 59A No. 63-20 - Núcleo El Volador, Medellín - Colombia. 


\section{ABSTRACT}

A bioassay was conducted with 88 genotypes of Solanum phureja to assess response to powdery scab of potato. To obtain plant material, tubers were planted in plastic bags of $3 \mathrm{~kg}$ capacity. Each plant was inoculated at 25 days after sowing, with direct application to the root of $10 \mathrm{~g}$ of infested soil with $7 \times 10^{6}$ sporeball. After 50 days of inoculation, in flowering stage, was observed the presence of root galls. Asymptomatic plants, without structures or symptoms of the pathogen were evaluated by PCR using specific primer to detect Spongospora subterranea f.sp. subterranea. The results showed that 57 genotypes had 100\% of incidence, 21 genotypes showed no disease, and the 10 remaining had intermediate values of incidence. For the cultivar Criolla Colombia $90.87 \%$ incidence was observed. The estimated average severity of all genotypes was between 0 and $4.68 \%$ for the resistant and susceptible genotypes, respectively.

Keywords: Sporeball, bioassays, incidence, severity.

\section{INTRODUCCIÓN}

Según Rodríguez (2010), las primeras papas cultivadas probablemente fueron seleccionadas entre 6.000 y 10.000 años atrás, al norte del lago Titicaca, en los Andes del sur de Perú. Allí, a partir de las especies silvestres Solanum bukasovii, S. canasense y S. multissectum, pertenecientes al complejo $S$. brevicaule, pudo haber dado origen a S. stenotomum, considerada la primer papa domesticada, la cual a través de repetidos procesos de poliploidización sexual podría haber dado origen a S. andigena. De otro lado, se considera que S. phureja fue seleccionada a partir de S. stenotomum por ausencia de período de dormancia en el tubérculo al momento de la cosecha, rápido desarrollo de los tubérculos y mejor crecimiento del cultivo.

Las papas cultivadas que se comercializan a nivel mundial se encuentran dentro de la especie Solanum tuberosum. Según Huaman y Spooner (2002) no existe un acuerdo entre los taxónomos del sitio de origen y clasificación de las papas, pero, se considera a $S$. tuberosum subsp. tuberosum como papas provenientes de las variedades nativas de Chile, caracterizadas por poseer una morfología poco variable, y adaptación para florecer y producir tubérculos en regiones de días largos. Por otro lado, estos autores mencionan que, S. tuberosum subsp. andigenum son papas provenientes de variedades nativas de los Andes.

S. phureja Juz. et Buk. es un grupo importante para el mejoramiento y desarrollo de nuevas variedades de papa, debido a sus excelentes características culinarias (Ghislain et al., 2006). Colombia es el mayor productor, consumidor y exportador de papas diploides en el mundo y posee una ventaja competitiva notable en razón de ser centro de diversidad y poseer gran aceptación por los consumidores, debido a las características organolépticas y nutricionales del tubérculo (Rodríguez et al., 2009). Actualmente, la papa criolla se distribuye en los Andes, desde Venezuela hasta el centro de Bolivia (Ghislain et al., 2006). 
Por otra parte, las enfermedades que afectan el cultivo de la papa son cada vez más severas. Tal es el caso de Spongospora subterranea $f$. sp subterranea agente causal de la sarna polvosa de la papa, importante enfermedad que limita la comercialización, el procesamiento y el período de almacenamiento de los tubérculos (Falloon, 2008; Qu y Christ, 2007). S. subterranea f. sp subterranea es un Plasmodiophorido que se caracteriza por la división nuclear cruciforme y la producción de quistosoros, los cuales son estructuras poliédricas, de color amarillo marrón que poseen un diámetro de 20-45 $\mu \mathrm{m}$ y están compuestos por las esporas de resistencia denominadas soros que en su interior contienen las zoosporas primarias con dos flagelos heterocontas (Jaramillo et al., 2008).

La liberación de la zoospora está regulada por el hospedero, la temperatura y las condiciones del suelo (Merz y Falloon, 2009). Merz (1993) observó que la liberación de las zoosporas en plantas de tomate fue a las cinco horas después de la interacción, mientras que, Jaramillo et al. (2008) encontraron liberación a las seis después de inoculación en plantas de papa. Las zoosporas dan origen al plasmodio y zoosporangios, los cuales pueden ser encontrados en las raíces, presentándose hasta 140 zoosporangios $\mathrm{mm}^{-2}$ (Falloon et al., 2003).

Los síntomas característicos del patógeno son formación de agallas en raíces y estolones, las cuales inician con un tamaño de $3 \mathrm{~mm}$ de diámetro, de color crema claro, que cuando maduran se tornan castaño oscuras. Similarmente ocurre en los tubérculos, donde se forman pústulas que se van uniendo hasta formar chancros que deforman el tubérculos. Las agallas y pústulas maduras poseen gran cantidad de quistosoros que se liberan dando un aspecto polvoriento (Harrison et al., 1997; Falloon, 2008)

Se han establecido algunas estrategias de manejo como es el caso de tratamientos químicos a la semilla (zinc, boro, sulfuros), rotación de cultivos y uso de tubérculos-semilla no contaminados. Implementar otras medidas fitosanitarias como el uso de variedades resistentes, y el diseño de métodos de detección temprana, pueden contribuir a reducir la severidad de la enfermedad (Falloon, 2008).

Una de las formas de cuantificar la presencia de S. subterranea en raíces es el uso de bioensayos. Según Merz et al. (2004) y Baldwin et al. (2008), las inoculaciones artificiales y bajo condiciones controladas (bioensayos), permite desarrollar cultivares resistentes, que en condiciones de campo sería un proceso largo, el cual requiere de varias repeticiones para asegurar una infección confiable con resultados consistentes en el tiempo. Sin embargo Merz et al. (2004) utilizan un bioensayos con base en inoculación líquida, mientras que, Baldwin et al. (2008), realizan inoculaciones directas al suelo con quistosoros.

En Colombia la sarna polvosa ha incrementado su incidencia en las zonas productoras de papa, y en especial en el departamento de Antioquia donde se presenta alta incidencia y severidad de síntomas de sarna polvosa en raíces, aunque eventualmente se observa en tubérculos. Por esta razón han sido desarrolladas gran cantidad de investigaciones que buscan conocer la biología básica del patógeno, la ecología del patosistema de sarna polvosas y los parámetros genéticos de la resistencia a la enfermedad con la finalidad de adelantar un manejo integrado de la misma (Corrales et al., 2012; Orozco et al., 2012a; Orozco et al., 2012b; Rendón et al., 2012; Rodríguez et al., 2013; Arcila et al., 2013a, Arcila et al., 2013b; Palacios y Cotes, 2013a; Palacios y Cotes, 2013b; Arcila et al., 2014 y Rodríguez et al., 2014)

El objetivo de esta investigación fue evaluar, en genotipos de S. phureja, la incidencia y severidad, en raíces, de los síntomas producidos por $S$. subterranea f.sp. subterranea bajo condiciones controladas, mediante inoculación directa de quistosoros al suelo. 


\section{MATERIALES Y MÉTODOS}

Esta investigación se realizó en la Casa Malla del Centro Agropecuario Paysandú, de La Universidad Nacional de Colombia, Sede Medellín, localizado en el corregimiento de Santa Elena, municipio de Medellín (Antioquia, Colombia), a una altura de 2550 msnm.

Se sembraron 88 genotipos de S. Phureja, de la colección de trabajo del Programa de Mejoramiento Genético en Papa de la Universidad Nacional de Colombia, cada uno con 11 repeticiones por material, dentro de los cuales se encuentra la variedad criolla Colombia, la cual es reconocida por su susceptibilidad a la enfermedad. Se procedió al llenado de bolsas de $3 \mathrm{~kg}$ de capacidad con suelo libre del patógeno. Al momento de la siembra, cada planta fue fertilizada con $20 \mathrm{~g}$ de 10 - 20 - 20 y se realizaron las labores propias del cultivo. El control fitosanitario se realizó con aplicaciones de Mancozeb al 80\%, para evitar la presencia de tizón tardío (Phytophthora infestans (Mont) de Bary). El ensayo se estableció en dos momentos diferentes y en ambas temporadas de siembra se tuvo presente el testigo Criolla Colombia.

\section{Inoculación}

Para la obtención del inóculo se siguió la metodología desarrollada por Alzate et al. (2008), la cual consiste en utilizar quistosoros extraídos a partir de suelo, en este caso procedente del departamento de Antioquia, municipio de La Unión, vereda Chuscalito, la cual tiene alta presencia de la enfermedad. El suelo fue secado a temperatura ambiente durante ocho días, luego fue macerado y pasado por un conjunto de tamices de 90 y $25 \mu \mathrm{m}$ respectivamente, recogiendo el suelo presente en el último tamiz. La concentración se determinó en cámara de Neubawer.

Después de conocer la concentración de quistosoros en el suelo se procedió a pesar $10 \mathrm{~g}$ de inóculo para aplicar 7,6 × 106 quistosoros, lo cual se hizo con la ayuda de una pala con la que se removió cuidadosamente el suelo de la bolsa y se procedió a aplicar directamente el inóculo en la raíz de la planta. La inoculación se realizó 25 días después de siembra. Asimismo, se realizaron riegos periódicos, para garantizar la humedad del suelo y favorecer el desarrollo de la enfermedad.

\section{Detección de síntomas}

Se detectaron síntomas al momento de la floración, 50 días después de la inoculación, cuando las flores estaban completamente abiertas. Se evaluaron 11 plantas por genotipo en el momento de floración, donde se evaluó la presencia de agallas producidas por S. subterranea f.sp. subterranea utilizando una escala diagramática (Ramírez et al., 2013), la cual presenta seis categorías de evaluación discriminadas así: 1) no se observan agallas., 2) presencia de la enfermedad entre $1-5 \%$, 3) $6-10 \%$, 4) 11 - 25\%., 5) 26 - 50\%., 6) > 50\%. A su vez, cada planta sin presencia de la enfermedad en campo fue llevada al laboratorio, donde se realizaron tinciones de raíces con el fin de descartar estructuras del patógeno en su interior mediante la observación al microscopio. Asimismo, se realizó la prueba molecular PCR (Polimerase Chain Reaction), sólo en plantas sin presencia visual de estructuras del patógeno.

\section{Extracción de ADN y PCR.}

La extracción de ADN de raíces asintomáticas, se realizó en bulk por genotipo, siguiendo la metodología del CTAB propuesta por DOYLE y DOYLE (1990), la cual consistió en un utilizar un buffer de extracción $(700 \mathrm{mM} \mathrm{NaCl}$., $50 \mathrm{mM}$ Tris $\mathrm{HCl} \mathrm{pH}$ 8.0., 10 mM EDTA., 2\% P/V de CTAB y 1\% mercaptoetanol). Posterior se realizó el lavado de la fase orgánica con fenol:cloroformo y la precipitación de los ácidos nucleicos con dos volúmenes de alcohol absoluto y Acetato de Sodio 3M. Finalmente el pellet generado fue disuelto en agua destilada estéril. La PCR se realizó utilizando dos pares de 
primer específicos (ambos amplían la región ITS del ADNr), Spo8 (5'CTG GGT GCG ATT GTC TGT TG 3') y Spo9 (5' CAC GCC AAT GGT TAG AGA CG 3') diseñados por Bulman y Marshall (1998) para amplificar la región de DNAr de 390pb y los primer SsF (5' GTC GGT TCT ACC GGC AGA CC 3) y SsR (5' GCA CGC CAA TGG TTA GAG ACG 3') diseñados por Qu et al. (2006) para amplificar una región del DNAr de $434 \mathrm{pb}$. Las reacciones de PCR incluyeron 0,5 $\mu \mathrm{M}$ de cada primer, $1 \mathrm{U}$ de Taq DNA polimerasa recombinante (Fermentas, Vilnius, Lithuania); 0,2 mM de cada dNTP., 1X de buffer de enzima $(100 \mathrm{mM}$ Tris- $\mathrm{HCl}(\mathrm{pH}$ 8.8), $1.8 \mathrm{mM} \mathrm{MgCl}$., $1 \mu \mathrm{L}$ de DNA y un volumen total de $25 \mu \mathrm{L}$. Las amplificaciones se realizaron en un termociclador T3 (Biometra, Alemania) con una desnaturalización inicial a $98^{\circ} \mathrm{C}$ por $3 \mathrm{~min}$, seguida por 40 ciclos de $94^{\circ} \mathrm{C}$ por $0,5 \mathrm{~min}, 57^{\circ} \mathrm{C}$ por $30 \mathrm{seg}, 72^{\circ} \mathrm{C}$ por 1 min y un período final de extensión a $72{ }^{\circ} \mathrm{C}$ por $10 \mathrm{~min}$. Luego de la amplificación, se tomaron $5 \mu \mathrm{L}$ de los productos de reacción y se separaron por electroforesis en gel de agarosa al 1,5\%., adicionando con $5 \mu \mathrm{L}$ de EZ VISION (10 mg $\mathrm{mL}^{-1}$ ). La visualización de las bandas se realizó bajo luz ultravioleta utilizando el sistema digital de análisis Bio Doc Analyze (Biometra).

\section{Análisis estadístico}

La incidencia de la enfermedad fue considerada como el porcentaje de plantas con una severidad mayor del $0 \%$. La severidad se tomó como la marca de clase de las seis categorías de la escala diagramática utilizada. Asimismo, se incluyeron cuatro subcategorías más con los siguientes valores: 1) 0\% sin presencia de síntomas o estructuras del patógeno observable al microscopio o PCR y; 2) 0,1\% de severidad si se detecta presencia del patógeno a través de PCR; 3) 0,25\% de severidad cuando se observan al microscopio plasmodios o zoosporangios en la raíces evaluadas; y 4) $1 \%$ de severidad si se observaban quistosoros en la observación al microscopio.
Para el análisis estadístico de las variables incidencia y severidad de la enfermedad se ajustó el valor del genotipo en cada ensayo ponderado por el valor del testigo (Criolla Colombia). Las variables incidencia y severidad de la enfermedad, al ser variables de porcentaje, en el primer caso que proviene de una distribución binomial, y en el segundo de una distribución pseudobinomial, se analizaron mediante un modelo lineal generalizado asumiendo una función de ligamiento logit. Se utilizó la metodología de estimación Bayesiana, obteniendo como estimados la media de la distribución a posteriori, la cual minimiza el riego de bayes bajo la función de pérdida cuadrática, y fue tenida en cuenta para la comparación de los tratamientos. Si estos intervalos se traslapan no hay diferencias significativas entre los tratamientos. Se utilizó el programa estadístico R (2009).

Por otro lado para explorar, la relación entre la incidencia y la severidad se empleó la fórmula propuesta por McRoberts et al. (2003), la cual considera que la relación entre la incidencia y la severidad está dada por la expresión $S=\alpha \ln (1-1)$, donde $\alpha$, es - 1/a, y "a" es el nivel mínimo de incidencia, $S$ es la severidad e I es la incidencia. Esta fórmula, es útil para el caso donde la incidencia incrementa desde un bajo valor (usualmente toma valores de cero) hacia un valor superior b (usualmente puede tomar valores explícitos en la escala del $100 \%$ o 1 en proporción). De igual forma, para estos análisis, se utilizó el programa estadístico R (R Core Team, 2012).

\section{RESULTADOS}

Según los valores medios estimados de incidencia, los genotipos se pudieron categorizar en tres grandes grupos donde 57 genotipos presentaron el 100\% de incidencia; 21 genotipos no presentaron la enfermedad; y los10 restantes presentaron valores intermedios para esta variable. Los 
genotipos que presentaron la mayor resistencia, es decir con $0 \%$ de incidencia y severidad fueron: 11, 27, 35, 40, 42, 87, 88, 89, 100, 110, 112, 113, 119, $129,131,132,133,140,142,143$ y Criolla Paisa (Figura 1). Cuando se realizó la prueba de PCR a los genotipos anteriores, no hubo amplificación de bandas características del patógeno (390- 434 pb) con los primers Spo8/Spo9 y SsR/Ssf.

Debido a que en este bioensayo la incidencia de la enfermedad agrupó de manera muy gruesa los genotipos, es necesario profundizar en sus valores de severidad. Entre los 57 genotipos susceptibles por incidencia ( $100 \%$ de plantas enfermas), la severidad osciló entre 0,5\% y 4,68\%, lo cual da una amplia respuesta de resistencia parcial de los genotipos a la infección de S. subterranea (Figura 2). Así dentro de este grupo podemos destacar los genotipos 4, 15 y 16 con valores de severidad superiores al $4 \%$. La variedad Criolla Galeras, es el genotipo siguiente en susceptibilidad con un valor estimado medio de severidad de 3,83\%.

De igual forma, dentro de los diez genotipos que conforman el grupo intermedio de incidencia encontramos una variabilidad entre $0,16 \%$ y $2,48 \%$ para el valor promedio estimado de la severidad. El testigo Criolla Colombia es justamente el que presenta el mayor valor de severidad dentro de este grupo. Las variedades comerciales Criolla Latina y Criolla Guaneña, también se encuentran dentro de este grupo, presentando valores de 0,50\% y 0.,33\%, respectivamente.

Al relacionar la incidencia con la severidad, en floración, a los 50 días después de inoculación, se obtuvo un índice de correlación del 69,57\% entre los valores observados y los ajustados por el modelo (Figura 3). Según la propuesta de McRoberts et al. (2003) de los diez genotipos con incidencia intermedia, seis de ellos se encuentran por encima de la curva de pronóstico, indicando que son genotipos susceptibles. Dentro de estos seis se encuentra la variedad Criolla Colombia, resultado que confirma su clasificación como variedad susceptible.

\section{DISCUSIÓN}

Nakayama et al. (2002), realizando un bioensayo con inoculación directa de quistosoros al tubérculo semilla, encontraron valores de severidad de la enfermedad entre 38,5 y 58,0 en las variedades Eniwa (considerado resistente) e Irish Cobbler (cultivar más sembrado en Japón, altamente susceptible), respectivamente. Estos mismos autores, mediante bioensayos con solución de quistosoros, encontraron valores entre 21,7 y $88,3 \%$ en las mismas variedades. Por otro lado, Houser y Davidson (2010), encontraron valores de severidad en el material susceptible VC967-2R/Y de 3.83\% y en el moderadamente resistente "Russet Burbank" de 1,25\%. En nuestro ensayo encontramos que el genotipo 4 con mayor severidad presentó un valor estimado de $4,68 \%$ el cual dista mucho de los resultados reportados por Nakayama et al. (2002) y se acercan a los que Houser y Davidson (2010), consideran como susceptibles. Esto muestra que en la comunidad científica en papa no hay acuerdo en qué condiciones absolutas debe reunir un genotipo para ser considerado resistente y/o susceptible a sarna polvosa, y esta clasificación se realiza relativa a los cultivares que se evalúan en cada ensayo.

Baldwin et al. (2008), inoculando con 2,5 x $10^{6}$ quistosoros, encontraron valores de $79 \%$ y $4 \%$, para la incidencia y severidad de la enfermedad, respectivamente. Iftikhar et al. (2007), encontraron que el cultivar Desiree, presentó los valores más bajos de incidencia con $24 \%$ y una severidad de menos del $1 \%$ en los individuos enfermos, mientras que el cultivar "Faisalabad", presentó un 44,3\% de incidencia de la enfermedad, con un valores de severidad entre el 1 y $10 \%$, para las plantas enfermas. Nitzan et al. (2008), evaluando con una escala diagramática 


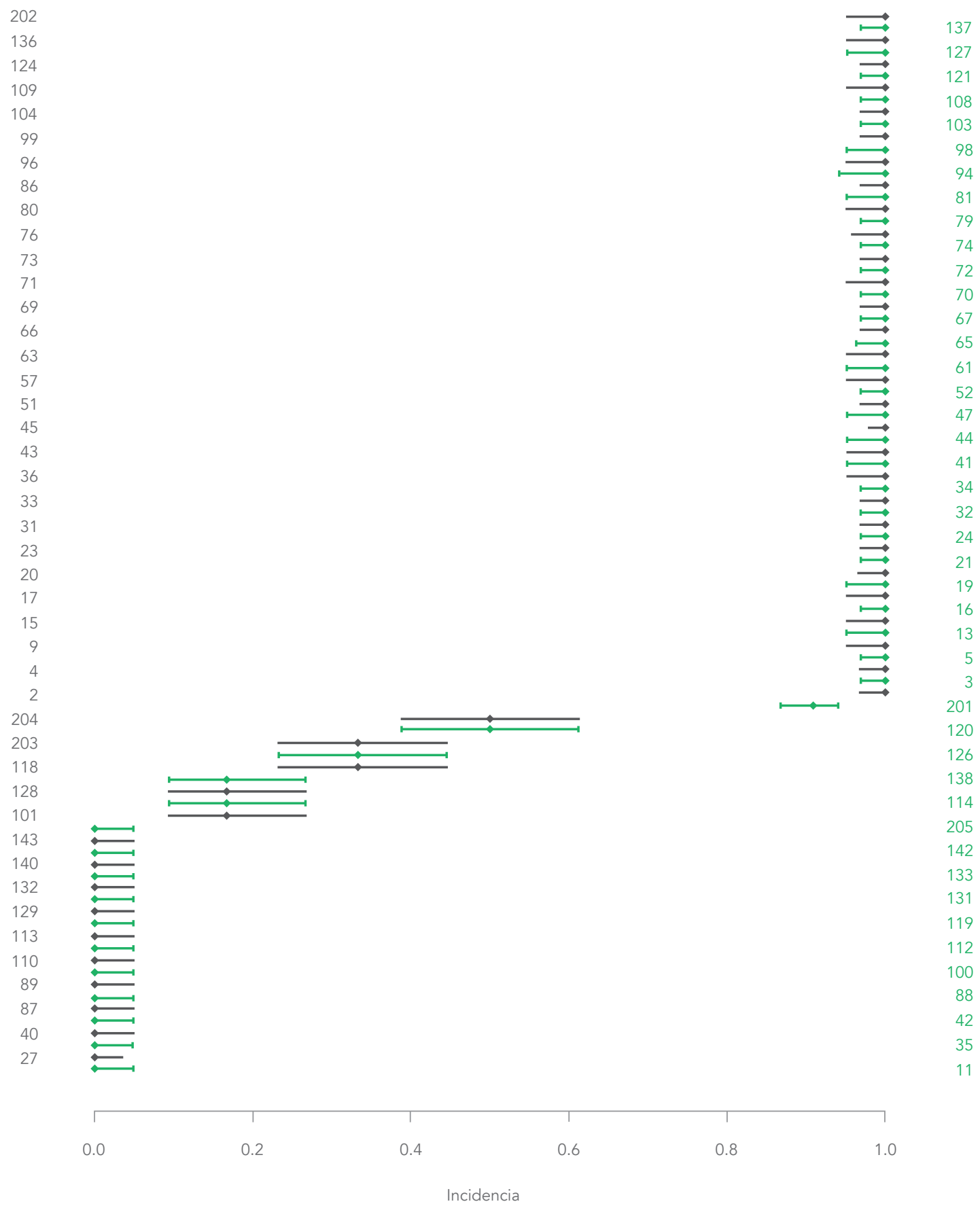

Figura 1. Valor medio estimado y su intervalo de alta densidad a posteriori de $90 \%$ de probabilidad para la incidencia a la sarna polvosa en 90 genotipos de plantas propagadas a partir de tubérculo. Las variedades comerciales son: Criolla Colombia (201), Criolla Galeras (202), Criolla Guaneña (203), Criolla Latina (204) y Criolla Paisa (205) 


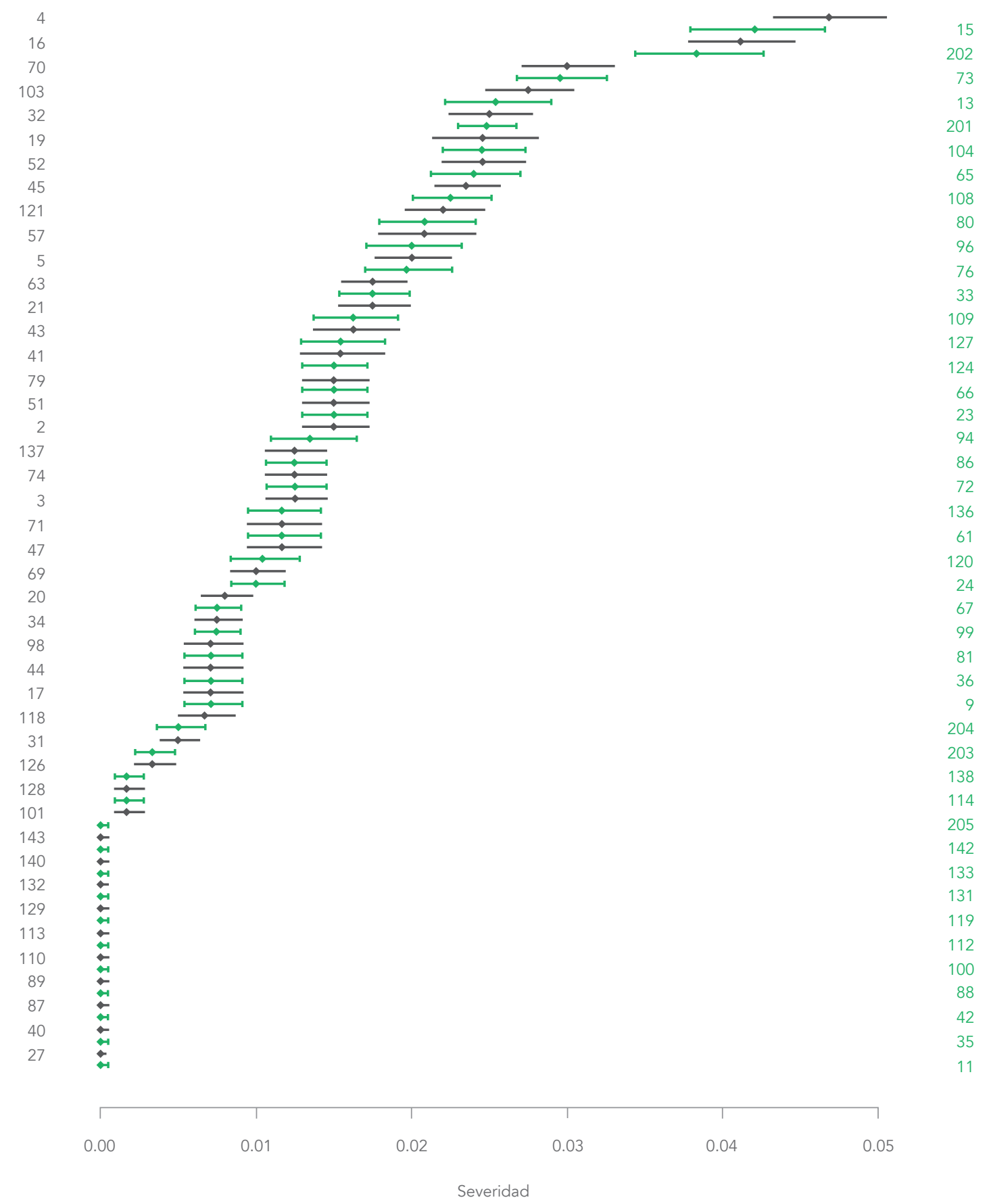

Figura 2. Valor medio estimado y su intervalo de alta densidad a posteriori de $90 \%$ de probabilidad para la severidad a la sarna polvosa en 90 genotipos de plantas propagadas a partir de tubérculo. Las variedades comerciales son: Criolla Colombia (201), Criolla Galeras (202), Criolla Guaneña (203), Criolla Latina (204) y Criolla Paisa (205) 
de cinco categorías $(0,1, \ldots, 4)$ evaluaron genotipos de $S$. tuberosum, dentro de los cuales se encontraban clones y cultivares comerciales, y encontraron a 16 genotipos de papa susceptibles a la infección en raíces destacando el cultivar "Shepody" con un valor medio superior a 2,5 en la escala de severidad. Como genotipo resistente reportan al clon PA98MN38-1 con un valor de severidad de 0,2\%. Estos tres estudios muestran que la severidad de la enfermedad es relativamente baja, y que aunque la incidencia y la severidad son dos parámetros de epidemiología vegetal para tener en cuenta en la clasificación de la resistencia de los cultivares, la incidencia en el caso del ataque de sarna polvosa está siendo más determinante. En esta investigación se obtuvieron resultados de incidencia y severidad similares a los reportados en los trabajos anteriormente mencionandos. En los bioensayos con S. phureja fue posible discriminar entre genotipos resistentes y susceptibles, inicialmente por su

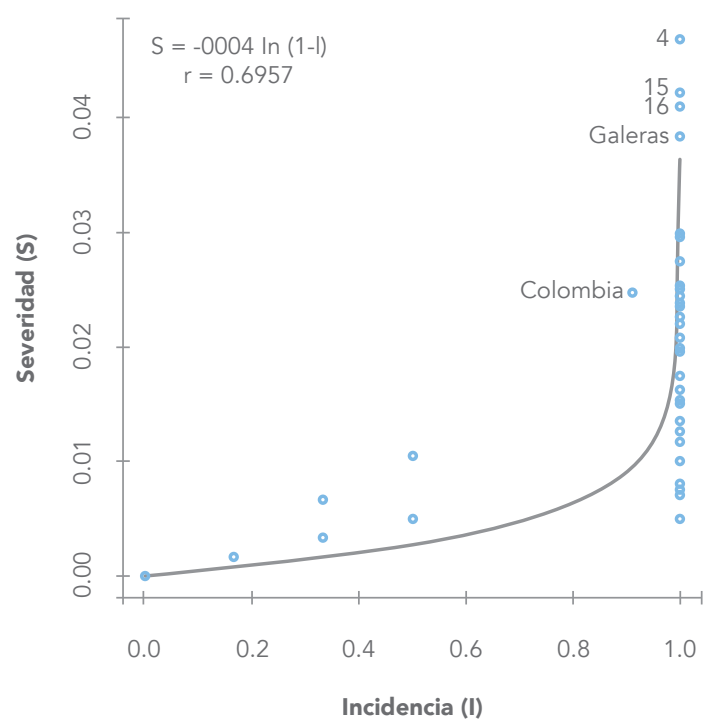

Figura 3. Correlación entre la incidencia y severidad de plantas procedentes de tubérculo en genotipos de $S$. phureja inoculados aplicación directa al suelo con quistosoros de S. subterranea incidencia y luego por su severidad, la cual es baja en comparación con evaluaciones de campo, pero entra dentro de lo reportado para los bioensayos con inoculación directa. En este ensayo, aunque se utilizó nivel de inóculo 7 × $10^{6}$ quistosoros por planta, la severidad de la enfermedad no fue tan alta, posiblemente por la influencia de otros factores como la temperatura y la humedad, anteriormente reportados, o por la germinación escalonada del quistosoro, como lo reportan Baldwin et al. (2008) y Lees et al. (2008).

Falloon (2008) sugirió que los mecanismos de resistencia no están bien entendidos, pero se ha demostrado que los cultivares resistentes presentan pocos zoosporangios y agallas en sus raíces en comparación con genotipos susceptibles. Este mismo autor indica que la resistencia genética es compleja porque varía desde altamente resistente hasta altamente susceptible, indicando una resistencia de tipo cuantitativa probablemente basado en efectos aditivos de algunos genes de resistencia. Genet et al. (2007) clasificaron materiales de papa como muy resistentes a los cultivares Gladiador, Red Rascal, moderadamente resistentes Russet Burbank, moderadamente susceptibles a Atlantic y Shepody, y muy susceptibles al cultivar Agria, corroborando la resistencia tipo cuantitativo. Esta misma variación continua de la expresión de la severidad de la enfermedad fue encontrada en trabajos realizados por Ramírez et al. (2013). Los resultados obtenidos en esta investigación, confirman un tipo de resistencia cuantitativa anteriormente reportada en especies relacionadas con S. phureja, logrando clasificar los 88 genotipos en muy resistentes, moderadamente resistentes, moderadamente susceptibles y muy susceptible.

Ramírez et al. (2013), realizó bioensayos a partir de esquejes de tallo lateral con 105 genotipos de S. phureja, y encontraron altos valores de incidencia y bajos valores de severidad para los síntomas 
de la enfermedad en raíces. Cuando evaluaron la relación entre estos dos atributos epidemiológicos encontraron una relación muy similar a la reportada en el presente estudio. Sin embargo el establecimiento de bioensayos en bolsas a partir de tubérculos, como es el caso del presente estudio, es mucho más fácil que los realizados a partir de esquejes de tallo lateral.

En conclusión el presente estudio permitió clasificar claramente la colección de trabajo de S. phureja de la Universidad Nacional de Colombia por su resistencia en raíces a la sarna polvosa, permitiendo con ello establecer los parentales a ser estudiados por esta característica. Además, esta investigación permitió establecer que bioensayos en bolsas, partiendo de tubérculo semilla y posteriormente inoculando quistosoros en el suelo, es una metodología viable para evaluar un gran número de genotipos, lo cual será útil en programas de mejoramiento genético de plantas.

\section{AGRADECIMIENTOS}

Los autores desean expresar su gratitud a la Universidad Nacional de Colombia Sedes Medellín y Bogotá, al Politécnico Colombiano Jaime Isaza Cadavid, a La Federación Colombiana de Productores de Papa FEDEPAPA y al Grupo de Investigación "Mejoramiento y producción de Especies Andinas y Tropicales" (COLCIENCIAS), que aportaron los recursos físicos, humanos, técnicos y financieros para adelantar esta investigación.

\section{REFERENCIAS}

1. Álzate D.E., Hoyos L.M. y González E.P. 2008. Factores que inciden en la liberación de zoosporas de Spongospora subterranea (Wallroth) Lagerheim f. sp. subterranea Tomlinson. Revista Facultad Nacional de Agronomía. Medellín 61: 4503-4510.

2. Arcila. I.M., González E.P., Zuluaga C.M. y Cotes J.M. 2013a. Alternate Hosts of Spongospora subterranea f. sp. subterranea identification in Colombia by Bioassay. Revista Facultad Nacional de Agronomía Medellín 66: $6987-6998$.

3. Arcila. I.M., González E.P., Zuluaga C.M., Marín M.A. y Cotes J.M. 2014. Efecto de la Infección de Spongospora subterranea f. sp. subterranea en Hospederos Alternos. Revista Facultad Nacional de Agronomía Medellín 67: 7261 - 7269.

4. Arcila. I.M., González E.P., Zuluaga C.M., Marín M.A. y Cotes J.M. 2013b. Comparación de dos métodos de detección de Spongospora subterranea f. sp. subterranea en raíces de plantas hospederas. Revista Facultad de Ciencias Básicas 9: 214 - 227.

5. Baldwin S., Genet R.A., Butler R.C. y Jacobs J. M. 2008. Greenhouse Assay for Powdery Scab (Spongospora subterranea f.sp. subterranea) resistance in Potato. Potato Research 5: 63-173.

6. Bulman S.R. y Marshall J.W. 1998. Detection of Spongospora subterranea in potato tuber lesions using the polymerase chain reaction (PCR). Plant Pathology 47: 759-766.

7. Corrales C., Zuluaga C.M., Cotes J.M., González-Jaimes E.P. 2012. Determinación de las condiciones óptimas para la liberación de zoosporas de Spongospora subterranea en bioensayos. TropicalPlantPathology37:239-245. 
8. Doyle J. J. y Doyle J. L. 1990. Isolation of plant DNA from fresh tissue. Focus 12: 13-15.

9. Falloon R.E. 2008. Control of Powdery Scab of Potato: Towards Integrated Disease Management. American Journal Potato Research 85: 253-260.

10. Falloon R.E., Genet A., Wallance A. y Butler R. 2003. Susceptibility of potato (Solanum tuberosum) cultivars to powdery scab caused by Spongospora subterranea, and relationships between tuber and root infection. Australasian Plant Pathology 32: 377-385.

11. Genet R.S., Braam W.F., Wallance A.R. y Falloon R.E. 2007. Susceptibility of potato cultivars and germplasm lines to powdery scab in New Zealand. www.spongospora.ethz.ch/ EUWorkshop07/index.htm. 05. Consultado en Marzo 11 de 2007.

12. Ghislain M., Andrade D., Rodríguez F., Hijmans R.J. y Spooner D.M. 2006. Genetic analysis of the cultivated potato Solanum tuberosum L. Phureja group using RAPDs and nuclear SSRs. Theoretical and Applied Genetics 113: 1515-1527.

13. Harrison J.G., Searle R.J. y Williams N.A. 1997. Powdery scab disease of potato a review. Plant Pathology 46: 1-25.

14. Houser A.J. y Davidson R.D. 2010. Development of a Greenhouse Assay to Evaluate Potato Germplasm for Susceptibility to Powdery Scab. American Journal Potato Research 87: 285-298.

15. Huaman Z. y Sponner D.M. 2002. Reclassication of landrace populations of cultivates potatoes (Solanum sect. Petota). American Journal of Botany 89: 947-965.
16. Iftikahar S., Rehman A., Asad S. y Burney K. 2007. Susceptibility of potato cultivares to Spongospora subterranea under field conditions. Park Journal Botany 39: 1329 - 1333.

17. Jaramillo S., Pérez G.A. y Hoyos L.M. 2008. Variación morfológica de quistosoros de Spongospora subterranea (Wallr.) Lagerh f.sp. subterranea. Revista Facultad Nacional de Agronomía Medellín 61: 4511-4517.

18. Lees A.K., Van de Graaf P. y Stuart W. 2008. The Identification and detection of Spongospora subterranea and factors affecting infection and disease. American Journal Potato Research 85: 247-252.

19. McRoberts N., Hughes G. y Madden L.V. 2003. The theoretical basis and practical application of relationships between different disease intensity measurements in plants. Annual of applied Biology 142: 191-211.

20. Merz U. 1993. Epidemiological aspects of powdery scab of potatoes caused by Spongospora subterranea. In: Hiruki C (ed) Proceedings of the 2nd symposium of the International Working Group on Plant Viruses with Fungal Vectors, Montreal, Canada, July 25-27, p. 104-106.

21. Merz U. y Falloon R.E. 2009. Review: powdery scab of potato increased knowledge of pathogen biology and disease epidemiology for effective disease management. Potato Research 52: 17-37.

22. Merz U., Martínez V. y Schwaerzel R. 2004. The potential for the Rapid Screening of Potato Cultivars (Solanum tuberosum) for Resistance to Powdery Scab (Spongospora subterranea) using a Laboratory Bioassay. European Journal of Plant Pathology 110: 71-77. 
with Root-Inducing Transferred-DNA Transformed Potato Hairy Roots. Journal Eukaryotic Microbiology 54: 465-467.

30. QuX.S., Kavanagh J.A., Egan D., Christ B. 2006. Detection and quantification of Spongospora subterranea f.sp subterranea by PCR in host tissue and naturally insfested soil. American Journal of Potato Research 83: 21-30.

31. R Development Core Team. 2012. R: A Language and Environment for Statistical Computing. R Foundation for Statistical Computing. Vienna, Austria. http://www.R-project. org/

32. Ramírez L.A., González E.P., Zuluaga C.M., Marín M.A., Morales J.G., Nústez C.E., Cotes J.M. 2013. Uso de esquejes de tallo lateral para evaluar la resistencia de genotipos de Solanum phureja a Spongospora subterranea f. sp. subterranea. Tropical Plant Pathology 38: $303-312$.

33. Rendón V.A., González E.P. y Cotes J.M. 2012. Heredabilidad de la resistencia a Spongospora subterranea f. sp. subterranea en una población de Solanum phureja a través de bioensayos. Revista Facultad de Ciencias Básicas 8: $70-87$.

34. Rodríguez L.E. 2010. Teorías sobre la clasificación taxonómica de las papas cultivadas nuevos cultivares de papa criolla para el departamento de Antioquia (Colombia). Agronomía. Colombiana 27: 289-303.

36. Rodríguez V., Marín M.A., Morales J.G., Cotes J.M. y Gutiérrez P.A. 2014. Sobreexpresión de genes en la interacción de Spongospora subterranea (Wallr.) Lagerh. y dos cultivares de Solanum phureja Juz. et Buk. Revista de Protección Vegetal 29: 20 - 32. 